Revista Iberoamericana, Vol. LXXIII, Núm. 220, Julio-Septiembre 2007, 437-452

\title{
LA APROPIACIÓN DE LA FIGURA DEL KAJCHA EN LA HISTORIA DE LA VILLA IMPERIAL DE POTOSÍ DE ARZÁNS DE ORSÚA Y VELA
}

\author{
por \\ OrLando Bentancort \\ University of Southern California
}

Reflexionando acerca del rol de la alegoría criolla e indígena en la Historia de la Villa Imperial de Potosí de Arzáns de Orsúa y Vela, Leonardo García Pabón sostiene que "la alegoría indígena sin dejar de ser barroca y participar del código del espectáculo, es un idioma social diferente al de los criollos” (“Indios” 437). ${ }^{1}$ García Pabón ve en la promesa del retorno del Inca ausente una marca singular que diferencia a la alegoría indígena de la criolla: "No sólo por la distancia que crea la división social entre colonizado y colonizador, sino porque la historia que los indios representan tiene la marca de una carencia: la muerte del Inca”. En este sentido, la distancia misma entre colonizador y colonizado, entre el pasado precolonial y el presente criollo, entre la separación del Inca del cuerpo social y la celebración del exceso de plata del Cerro de Potosí, es el escenario en el que se despliega la singularidad diferencial indígena, aún cuando se halle ésta representada en un aparato de representación criollo.

Para García Pabón, la fiesta potosina en Arzáns expresa los contrastes, distancias y contradicciones de una desigualdad que es desplegada utilizando técnicas barrocas de composición: "Si contrastamos la imagen criolla más requerida por ellos, el cerro, que representa la abundancia de bienes, con la imagen india más exaltada, la ausencia de su Inca, podemos ver en este elocuente claro/oscuro barroco cómo se dibujan los pliegues ideológicos de la fiesta potosina”. El evento colonial queda inscrito en la representación barroca, haciendo posible la expresión del contenido histórico de la desigualdad colonial. Como sostiene García Pabón: “unos hablan desde la riqueza y otros desde la pobreza, unos son vencedores, los otros vencidos, unos se auto-contemplan en el espejo de su lujo presente, los otros reflexionan sobre un mundo que se ha dado la vuelta; en una palabra, las desigualdades sociales e históricas también constituyen la forma barroca en América y hablan por ella”. En esta línea de pensamiento, las técnicas barrocas utilizadas por Arzáns permitirían la creación de pliegues en los cuales irrumpe "la carga simbólica de esta representación del Inca discordante en medio de la armonía procesional. El Inca/cacique es, a la vez, lo más real y lo más irreal de estos cuadros” (436).

${ }^{1}$ Sobre el rol de la ambivalencia de Arzáns hacia la alteridad (y/o subalternidad) en su Historia de la Villa Imperial de Potosí véanse Herrmann; García Pabón “The Indian”. Para un análisis de las técnicas de composición de Arzáns véase "Niveles diegéticos en las crónicas de Arzáns”. Hanke y Mendoza analizan el contexto histórico, literario y cultural de Arzáns en su introducción. 
Sin embargo, cabe preguntarse por los límites críticos y políticos de tal técnica de representación barroca, ya que ¿no es acaso la singularidad diferencial indígena apropiada por este sistema de representación colonial y criollo que hereda la separación del Inca y el cuerpo social a la vez que reduce la singularidad indígena a la ausencia del Inca? De hecho, para someter a crítica tal sistema de representación, sería conveniente llevar el argumento un paso más allá y preguntarse por la naturaleza de la diferencia material, es decir, de la singularidad indígena en el contexto de la diferencia entre fuerzas materiales inestables que no pueden ser reducidas a una identidad superior. Si las fuerzas que mantienen un contexto social nunca permanecen idénticas (por presuponer otras relaciones de fuerzas continuamente desplazadas) ya que viven en un estado de continuo desequilibrio, desplazamiento o différance, cabe entonces preguntarse por la génesis de producción de tales relaciones de poder-fuerza, y así agregar a la distancia entre pasado/presente, Inca/ cuerpo-colonial, criollos/indígenas, una diferencia más. Esta diferencia sería la distancia entre el productor y el producto; en otras palabras: la distancia entre la veta de metal en el cerro de Potosí y el kajcha (minero indígena que roba metales los fines de semana y los días de fiesta). ${ }^{2}$ Una vez introducida la nueva perspectiva que da la distancia entre el productor y el producto en la división colonizador/colonizado, cabe preguntarse por las potenciales resistencias o amenazas al sistema de fuerzas (aparentemente estables e idénticas) que la introducción de tal singularidad diferencial pueda traer. ¿Hasta qué punto la amenaza del trabajador indígena que se apropia de los metales (kajcha) posee suficiente poder como para desestabilizar el aparato representacional que lo captura? ¿Hasta dónde deconstruyen éstas las líneas de divergencia al sistema moderno/colonial que las engendra y hasta qué punto reproducen las mismas estrategias de poder? ¿Es la desigualdad moderno/colonial atrapada en la transculturación criolla como síntesis de unidad superior, o es, por el contrario, interrumpida por el espectro del productor indígena que se apropia de su producto haciendo uso de su propio saber? ¿Es posible revertir esta desigualdad para y en la representación y trazar una línea desterritorializadora que problematice la distancia entre un productor tributario colonizado y un producto del cual depende el sistema colonial entero?

Con el propósito de evaluar el alcance de la presencia divergente de la singularidad indígena en la Historia de la Villa Imperial de Potosí de Arzáns de Orsúa y Vela, propongo analizar las operaciones histórico-libidinales (conexiones, disyunciones y conjunciones) que subordinan al trabajador indígena minero a la representación hegemónica del mundo

${ }^{2}$ El kajcheo era una práctica de los trabajadores mineros del siglo XVIII (aunque con antecedentes en el siglo XVI y XVII) que consistía en trabajar en beneficio propio desde los sábados por la noche a los lunes por la madrugada. El metal se vendía en la Plaza del Gato en Potosí, y el tráfico de metal se denominaba "rescate" (Cole 14; Tandeter 73-102). Los kajchas, que representaron un problema hasta el momento de la independencia, podrían llegar a ser entendidos como una manifestación de resistencia al poder colonial, ya que robaban metal y luego lo vendían en el mercado del Gato. Una prueba del carácter relativo de tal resistencia es la propia polémica que generaron los kajchas, tal como está registrada por José Luis Capoche (también defensor de los intereses de los azogueros) en su Relación, quien concluye en la necesidad de tolerar (aunque controlando) a los ladrones de metal, ya que indirectamente facilitaban la circulación de mercancías y agilizaban la economía (Capoche 160). 
moderno-colonial (separando el productor del producto). ${ }^{3}$ A través del análisis del kajcheo (práctica que consiste en robar metales los fines de semana o días de fiesta en las minas del Potosí colonial) pretendo analizar aquellas operaciones que efectúan una desestabilización de estas representaciones hegemónicas y que pueden ser resumidas en la distancia entre el minero y la veta de mineral. Me propongo analizar las diferentes conexiones, disyunciones y conjunciones que producen (o conjuran) el afuera del sistema hegemónico, es decir: el espectro del trabajador indígena como límite exterior del proceso, que es también el motor de la extracción minera en gran escala más importante en la historia de la colonización del Alto Perú. El método de este trabajo consiste en analizar el margen de desterritorialización y reterritorialización (respecto a al sistema de inscripciones moderno/colonial) que introduce la práctica del kajcheo (robo de metales seguido de su procesamiento en aparatos de amalgamación portátiles) en el texto de Arzáns de Orsúa y Vela. Utilizo la noción de decodificación-desterritorialización en el sentido dado por Deleuze y Guattari en su dialéctica de territorialización, en la cual la decodificación (o desterritorialización) es una función propia de los cambios radicales, tanto los producidos por el capital como aquellos cambios revolucionarios mediante los cuales se abandona cierto territorio o estado de cosas para alcanzar un umbral. ${ }^{4}$

El carácter espectral, subterráneo, subalterno y subrepresentacional del trabajador indígena señala un umbral residual que amenaza el sistema de producción capitalista. Ni activo ni pasivo, ni interno ni externo, el espectro es un evento potencial impasible que excede los límites de la representación (Deleuze, Logic 211). Es posible asociar la noción de espectro de Deleuze con la noción de espectro en Derrida como momento irreductible de un futuro-por-venir, con el propósito de detectar el límite externo del proceso de desterritorialización capitalista. Si el espectro es un evento que sucede en un estado de

\footnotetext{
${ }^{3}$ Estas operaciones, o síntesis del inconciente, que proponen Deleuze y Guattari en el primer capítulo de Anti-Oedipus. Capitalism and Schizophrenia, sirven como método materialista-histórico y libidinal de análisis ya que permiten poner en relación la producción social y la producción del deseo. Las síntesis del inconciente sirven para pensar no solo cómo se despliegan los sistemas de representación modernos coloniales, sino las condiciones de posibilidad de producción material de tales representaciones. Las tres síntesis son: primero, la síntesis conectiva de la producción (composición abierta de signos); segundo, la síntesis disyuntiva del registro (que inscribe la distancia entre los signos); y por último, la síntesis conjuntiva del consumo (que forma sujetos residuales como efecto de las síntesis anteriores). Siguiendo a Kant, Deleuze y Guattari consideran necesario someter a crítica los usos metafísicos y transcendentes de cada síntesis y examinar sus condiciones de posibilidad (74).

${ }^{4}$ Se trata de una revolución permanente de los modos de producción (Marx) que produce un doble movimiento de desterritorialización y reterritorialización ya que por un lado se engendra un umbral externo al proceso, un elemento excremental, esquizo, cambiante o residual que se estigmatiza como una amenaza y, por otro lado, se reterritorializa los flujos decodificados en la propiedad privada y la abstracción cuantitativa. Por lo tanto, es preciso distinguir entre la desterritorialización producida por el capital (negativa, fetichista, y recodificadora) y la desterritorialización absoluta que se asoma a un Evento, a lo que Deleuze y Guattari llaman una "nueva tierra”, un mundo por venir. Para una discusión detallada de la dialéctica de Deleuze y Guattari en relación con la representación capitalista ver: Anti-Oedipus 240-61, y los teoremas de desterritorialización de A Thousand Plateaus 174-78, 232-309.
} 
cosas y es expresado en un lenguaje utilizado por una determinada comunidad, es también un efecto desplazado del doble proceso de desterritorialización y reterritorialización capitalista. Repetir el espectro, traerlo, insistir en la leyenda, es traer lo negado, excluido, el afuera del capital. Cuasi-noumenal e imposible, el espectro-evento es el elemento desestabilizador de las series que distribuyen el exceso de plusvalía por un lado y la falta inyectada por el sistema simbólico de recodificación por otro. Para que el saber metalúrgico posea un poder de desterritorialización más fuerte que el capital, debe ser conectado al espectro del trabajador indígena, ya que éste puede tener un efecto desestabilizador en el sistema acreedor-deudor que impera en la colonia. ${ }^{5}$

El espectro es la memoria borrada de la materia de la cual esta hecha la riqueza, la memoria desplazada hacia el límite externo del sistema bajo el efecto del capital que intenta recodificar este espectro de desterritorialización absoluta en el marco de la legalidad, la abstracción cuantitativa y la propiedad privada. Retomando el problema arriba planteado es conveniente preguntarse hasta qué punto podemos pensar que el kajcha que se apropia de los metales es un espectro-evento, un umbral externo a la decodificación capitalista y la remodificación. En otras palabras, ¿hasta dónde el kajcha representado en el texto barroco de Arzáns constituye un límite previo al momento en que la Historia de la Villa Imperial de Potosí se narrativiza en una lógica que subordina la singularidad diferencial indígena en el emergente sistema de identidad criolla? ${ }^{6}$

\footnotetext{
${ }^{5}$ El capitalismo presupone la acumulación primitiva, que a su vez necesita de la violencia del sistema acreedor-deudor. Es Nietzsche quien vio en la equivalencia entre dolor y deuda a pagar el fundamento de la violencia moral y legal que se impone sobre los sujetos históricos, sirviendo tal violencia como fundamento de las costumbres y de los sistemas tributarios (493-532). El capitalismo vuelve infinita la deuda para con la sociedad al mostrar al capital como elemento filial del trabajo y narrar el desequilibrio entre los pagos y la ganancia en términos de un milagro preestablecido, para lo cual necesita del sistema acreedor-deudor, reterritorializándose en la violencia moral (Deleuze y Guattari Anti-Oedipus 197-247). La historia de la acumulación primitiva se reduce al proceso histórico de separación del productor de su producto, evento que pertenece a la prehistoria del capital y es condición de posibilidad "And this history, the history of their expropriation, is written in the annals in letters of blood an fire” (Marx 875). Hay acumulación primitiva cada vez que hay un aparato de captura, cada vez que hay una violencia preestablecida y legal por parte del Estado y que, a diferencia de la "violencia ilegal" se usa contra las diferencias anómalas que amenazan la miracularización del sistema meta-estable del sistema acreedor-deudor. Esta violencia precede el modo de producción capitalista y constituye el modo necesario a través del cual actúa el Estado (Deleuze y Guattari A Thousand 447).

${ }^{6}$ Me refiero a la concepción de subalternidad como límite externo a la producción de hegemonía como aparece en Spivak: "the absolute limit of the place where history is narrativized into logic" (16). Como sostiene Williams, "This limit, and the experience of finitude that promises, inaugurates not the stabilization of heterogeneity -not the positive articulation of social signifiers around staterelated or controlled processes of transculturation -but the emergence of radical heterogeneity as persistent demand for a political and cultural thought that is grounded in the disjuncture and fragmentation that lies on the other side of hegemony and on the other side of hegemony's traditions and cultural histories” (70).
} 
El KAJCHEO COMO DESPLAZAMIENTO DEL LíMITE EXTERNO DEL SISTEMA ACREEDOR-DEUDOR

Desde la instauración de la mita en 1571 por Toledo, las provincias del Alto Perú eran obligadas a cooperar con trabajadores tributarios (mitayos) que proveían a Potosí de mano de obra barata. ${ }^{7}$ Pero las frecuentes fugas de trabajadores tributarios, así como el tráfico ilegal de estos indios mitayos por parte de los dueños de ingenios (azogueros) constituían fuertes límites al "buen" funcionamiento de la mita. En este contexto es que hay que entender el funcionamiento del kajcheo como apropiación directa e "ilegitima” del producto del trabajo por parte de los mineros indígenas. Como explica Enrique Tandeter en su libro Coercion and Market: "The kajcheo, then, must be placed among many other forms of direct appropriation of ore beyond wage remuneration which served to attract potential miner workers” (90). Siguiendo esto, se puede ver que el kajcheo es un aliciente, un modo de atraer trabajadores que de otro modo no querrían trabajar. Se puede afirmar que el robo de metales funciona como un suplemento del trabajo tributario (el trabajo ordenado por el sistema acreedor-deudor) y, desde esta perspectiva, favorece el funcionamiento del sistema de producción. Tal es la paradoja de este tipo de extracción de mineral caracterizada por la suspensión carnavalesca y la apropiación directa del producto del trabajo por parte del trabajador. Si bien el kajcheo supone una pérdida, se trataría de una pérdida tolerada por el sistema capitalista (un modo de buscar incrementar las ganancias incluso a partir de las pérdidas). En este sentido, el kajcheo es la expresión de las crisis, contradicciones e insuficiencias propias de un modo de producción que requiere de la dominación violenta mediante la implementación de trabajo tributario y de la creación hegemonizante de deseo para llevar a cabo la empresa de acumulación primitiva en conjunción al sistema acreedor-deudor.

El kajcheo es un efecto del carácter inestable del modo de producción, así como su amenaza. En palabras de Tandeter: "However, the kajcheo had specific negative consequences for mining entrepreneurs and even for the city's civil authorities. The most general was the development of a truly independent sector in Potosí's mining industry" (90). Se trata de una práctica ambivalente, pendular, que oscila entre suplementar la extracción de plusvalía y amenazar la acumulación primitiva colonial. Tolerado, incluso celebrado por cronistas como el propio Arzáns, el kajcha se erige en espectro de los dueños de ingenios de amalgamación criollos o españoles, siendo, simultáneamente, el efecto y

\footnotetext{
${ }^{7}$ La mita potosina fue un sistema de trabajo forzado que distribuía a los trabajadores mineros según turnos y fue introducida por el virrey Francisco Toledo en 1572. Es necesario destacar, siguiendo a Bakewell, que la mita potosina, junto a la introducción de la amalgamación mediante mercurio, fue un elemento decisivo para aumentar dramáticamente la producción de metales preciosos en Potosí luego de la visita del virrey Toledo. Si bien este no es el lugar para extenderse en el problema de la mita, habría que destacar que la misma fue la formalización y transformación de prácticas anteriores como la mita incaica y la encomienda. La distribución del trabajo y el pago de los sueldos estaba en manos de administradores coloniales, dependiendo los azogueros (dueños de ingenios de amalgamación) de los corregidores y veedores reales en la asignación de mitayos. La bibliografía acerca de la mita es extensa, pero entre los libros más significativos se hallan Bakewell; Cole; Tandeter; González Casasnovas; Saignes; Zavala.
} 
la negación del sistema, su condición de posibilidad y de imposibilidad: el kajcheo es el pharmakon del significante colonial.

Entre los elementos propios del kajcheo que amenazan la propiedad privada y la extracción de plusvalía hay que contar con el modo de organización de los kajchas. De hecho, se organizaban en bandas, pandillas y hordas, es decir, en multiplicidades anómalas y cambiantes, ilocalizables y subterráneas, como las mismas venas de mineral de las cuales se apropian. Como describe Tandeter, "Extraction of ore by the kajchas was accomplished in gangs that included a leader charged with the actual task of breaking off ore from a vein and four or more companions who carried the ore out of the shaft" (90). Los kajchas eran el crimen organizado de las minas de Potosí que se conformaban alrededor de un líder. Las multiplicidades anómalas de kajchas invadían las minas por las noches y los fines de semana y eran guiadas por un barretero: "The leader must have been one of the most highly qualified workers in the mining operation, one of the unruly pickmen (barreteros)" (90). Los líderes barreteros eran los que seguían la veta en la mina, detalle significativo, ya que estos trabajadores poseían un saber subalterno que los conectaba directamente con los medios de producción. Es significativo que los trabajadores que tienen una conexión directa con la veta, los mejor entrenados y los que son más indispensables para la extracción (ya que encuentran y siguen las vetas de mineral) sean los que lideran a quienes se apropian directamente de los medios de producción y del producto. Uno de estos líderes fue Agustín Quespi, cuya historia cuenta Arzáns en su monumental Historia de la Villa Imperial de Potosí.

El kajcha es representado por Arzáns como un sujeto valeroso (característica que lo acercaría al código moral español) y como un sujeto que causa problemas al Estado y a la iglesia (característica que lo alejaría del marco de legalidad de la colonia). En palabras de Arzáns: “Así le sucedió a un valiente indio, pues entre los gustos del efecto de su braveza andaba con el temor de su ruina, y muy al cabo estuvo de experimentarla. Veamos, pues, algo de sus hechos y prisión que tanto disgusto acarreó a los jueces eclesiásticos y seculares” (200-1). ${ }^{8}$ Arzáns plantea la coexistencia de dos cualidades que deberían ser contradictorias en el sistema hegemónico de representación colonial, ya que la virtud “valor” debería, obviamente, ser acompañada de cierta obediencia a la autoridad. Luego de presentar el caso de Agustín Quespi, como un caso paradójico de disyunción inclusiva entre valor y marginalidad respecto a la ley, Arzáns procede a explicar la valentía de Agustín. El modo de explicar el valor de este kajcha no es una identificación inmediata con el código moral del colonizador, sino con el territorio del cual procede, ya que en dicho territorio todas las razas experimentan valor. En palabras de Arzáns: "Su nombre, pues, es Agustín Quespi; su patria esta Villa, donde siempre se ha experimentado valor en los hijos de los españoles, en los indios y mestizos, en los mulatos y negros” (201). Agustín posee cualidades que son propias de los españoles porque son propias de un territorio en el cual tanto los españoles como los criollos, mestizos, indios y negros poseen tales virtudes. Desde una perspectiva geo-histórico-libidinal, el valor, en cuanto expresa una configuración territorial, es una marca de poder, de propiedad y de distancia territorial.

${ }^{8}$ Todas las citas de la Historia en este trabajo proceden del tomo III. 
Arzáns ex/propia las virtudes de los españoles y se las atribuye al territorio. La cualidad “valor”, no es privilegio exclusivo de los españoles, sino de todos los grupos étnicos. De este modo, Arzáns no está haciendo un uso exclusivo de la disyunción (que distribuiría cualidades a este sujeto $o$ a aquel sujeto), sino que está haciendo un uso abierto e inclusivo (aunque únicamente dentro del territorio), recorriendo la distancia territorial misma que es la fuente mítica de esta virtud y que se expresa en kajcha de un modo privilegiado. Arzáns conecta los diferentes grupos étnicos a través de una cualidad que cesa de aparecer bajo el signo de la disyunción exclusiva a condición de aparecer dentro del territorio de Potosí, haciendo un uso negativo y restrictivo de la disyunción para todo territorio que no sea Potosí.

Sin embargo, luego de atribuir cualidades propias de un español a un kajcha, y de explicar que son cualidades propias de todos los habitantes de la villa, Arzáns proporciona la génesis de tales cualidades territoriales por medio de la filiación y educación en el código moral español. En palabras de Arzáns: “Criólo un vizcaíno que también era valiente y diestro en las armas, como lo fue el capitán don Miguel de Sopeña, y es este indio feligrés de la parroquia de San Martín” (200). En otras palabras, blanquea a Agustín al decir que un vizcaíno lo educó, al tiempo que estabiliza su carácter marginal respecto a la ley y a la iglesia, enfatizando su carácter de feligrés de la parroquia de San Martín. Arzáns presenta al kajcha no como alguien absolutamente desterritorializado (habitando un afuera de la ley), sino como relativamente desterritorializado (instalado en el margen interno de la ley), ya que fue educado por un vizcaíno y es cristiano. Al narrativizar la Historia Arzáns localiza a Agustín en el borde interno de la ley y así lo estabiliza y regulariza, inscribiéndolo en el interior de un código moral europeo aceptable. En otras palabras, excluye cualquier característica amoral o desestabilizadora de las cualidades de Agustín.

No obstante, el temor desproporcionado que despierta Agustín, indica que si bien el valor es una cualidad que expresa el territorio de Potosí (haciendo un uso abierto e inclusivo de la disyunción) con el propósito de regularizar al kajcha e incluirlo en el marco de la ley, el líder de kajchas posee estas cualidades de modo superlativo. La virtud de Agustín aparece bajo el signo de exceso. En palabras de Arzáns: "Hízose tan temido en el Cerro que el más bravo español huía de su encuentro y los veedores y alcalde mayor de minas experimentaron fieras resistencias cuando iban a prenderlo por quejas de los azogueros que decían les disfrutaban las labores; y si resistían los guardas los maltrataba y aun veces hubo que los azotó con indecencia” (201). En este sentido, el valor de Agustín Quespi ya no es el valor de los españoles como negación del valor de los locales (uso colonial negativo y dialéctico de la cualidad) así como tampoco es el valor como expresión de un territorio (uso polívoco y abierto del valor atribuible a todas las razas de un territorio) sino que es un valor que produce temor y amenaza. El valor que Arzáns atribuye a Agustín en grado excesivo, aparece bajo el signo de falta en los españoles y criollos azogueros. Si bien Arzáns presenta a Agustín Quespi dentro del marco de la ley (al inscribirlo en un código moral colonial binario) y del sistema criollo (haciendo un uso territorial, abierto y polívoco) lo desplaza luego hacia un límite externo a la ley en el cual Agustín Quespi es el punto en el que se expresan estas cualidades de un modo superlativo. El carácter 
ambivalente y liminar del kajcha se funda en su exceso de valor, que se traducirá en falta de valor entre los criollos dueños de los ingenios de amalgamación. Arzáns identifica al kajcha haciendo uso de una cualidad propia de los españoles pero lo distancia de los mismos conforme avanza la presentación de Agustín. Arzáns desterritorializa el "valor” (al expropiarlo de los españoles), lo reterritorializa en Potosí (al atribuirlo a los habitantes de Potosí), pero lo potencia en Agustín, en quien aparece de un modo superlativo.

Si bien Agustín Quespi vive al margen de la ley y no en un afuera absoluto (por tener educación europeizante y ser cristiano), la resistencia que opone a su captura problematiza su posible inclusión en la ley. Si la resistencia es una expresión de autodeterminación, de capacidad de actuar, entonces, esta resistencia a su incorporación-subordinación, coloca a Agustín en un plano más desterritorializado respecto al de la identidad múltiple, hibrida e inclusiva. En otras palabras, el kajcha es temido y representa una amenaza debido a la resistencia que opone a los criollos, al punto en que la utilización de la violencia lleva al propio Arzáns a utilizar la palabra “indecencia” al referirse al modo en que Agustín utiliza la violencia contra los guardas. En este sentido, la celebración (investidura históricolibidinal) que hace Arzáns del kajcha problematiza su inscripción en el código moral europeo así como su pertenencia al territorio, desplazando tanto los usos inclusivos como los restrictivos de la disyunción para tornar a Agustín en un exceso barroco que escapa a los códigos que lo hacen posible. Arzáns no solo celebra la cercanía de Agustín a la ley (educación filial y cristianismo), sino también el modo en que el exceso de virtud se transforma en una resistencia a la ley. Sin embargo, ¿se puede afirmar sin más que Agustín habita el lado externo de un umbral de tolerabilidad? Los párrafos analizados sugieren que el uso inclusivo, criollo, de la disyunción desplaza a Agustín pero no tiene suficiente fuerza para producir una conexión directa entre el productor y el producto, así como tampoco una interrupción del sistema acreedor-deudor. La plusvalía de valor de Agustín produce un excedente que amenaza a la extracción de plusvalía por parte de los medios de los dueños de producción, pero Arzáns no considera que esta amenaza sea un signo de un mal irrevocable, como lo sería la deconstrucción absoluta del sistema (representado en el sistema de puentes y galerías), o una amenaza de insurrección.

"Sacar” metal violentamente es sinónimo de conectar de modo directo (e ilegal) al productor con el producto. En el texto de Arzáns leemos: “Teníanlo por su capitán muchos cacchas (que son los que van a sacar metal los días de fiesta violentamente, aunque lo trabajan a fuerza de sus brazos y riesgo de la vida en todo)” (201). Tal apropiación directa del producto por parte del productor es traducida al recorrido de una distancia entre el minero y la veta de mineral que solo puede ser llevada a cabo mediante la violencia (causa temor en los españoles y criollos). Agustín no es únicamente un héroe proto-romántico criollo que azota a los españoles y resiste a los alcaldes y autoridades produciendo resquemor entre los dueños de ingenios de amalgamación, sino alguien que se apropia de aquello que le "pertenece" a los dueños del capital y que lo separan del producto de su trabajo.

Sin embargo, no se debe perder de vista que los kajchas sacan metal violentamente "los días de fiesta”. ¿Es esta apropiación directa del producto por parte del productor una suspensión carnavalesca de las relaciones de producción, una expresión más de la fiesta 
barroca que solo puede representar a la singularidad indígena (incluso cuando es más violenta y molesta) en la representación criolla, por medio de la representación criolla y para la representación criolla? ¿O se trata de una violación de la propiedad privada que atenta contra las bases morales (sistema acreedor-deudor) de la colonia? El problema consiste en ver si esta conexión directa y violenta que cubre la distancia entre el productor y el producto produce una divergencia lo suficientemente fuerte como para pasar el umbral de tolerabilidad por parte de los dueños de los medios de producción, esto es: los azogueros mismos.

A pesar de ofrecer resistencia a su prisión y de azotar "indecentemente" a sus represores, Agustín no es nocivo, no representa una amenaza para Arzáns: “No era nocivo este indio Agustín en las labores corrientes, porque cuando él iba a sacar metal llevaba su avío y dinero para lo que se le ofreciese, herramienta y cuatro compañeros que llaman apiris” (201). Más allá de la obviedad que supone ver la ambivalencia de Arzáns a la hora de calificar a Agustín, es necesario preguntarse por la investidura histórico-libidinal que guía su evaluación. Arzáns dice que Agustín no era nocivo en las labores corrientes, es decir, no era nocivo para la división del trabajo en el marco de la organización regular del trabajo por turnos (opuesto a la suspensión carnavalesca de los fines de semana). Si Agustín no representaba una amenaza para el trabajo regular, su interrupción podría ser tolerable, ya que se produce en el marco de la continuidad laboral y la división colonial del trabajo. Incluso su solidaridad para con los apiris (cargadores de metal) aparece como signo del buen funcionario: el buen trabajador, que viola la ley solamente dentro del marco de la ley. Arzáns agrega: "Verdad es que iba con un par de pistolas, porque como no tenía mina propia entraba en las desiertas, o por algunas lumbreras y comunicaciones a las ajenas, y sacaba el metal sin derribar puentes ni hacer daño considerable” (201). Luego de asegurar que Agustín era inofensivo, Arzáns agrega, en tono apologético, que el kajcha iba armado con armas de fuego, apresurándose también a decir que no entraba en minas de otros (es decir, no violaba la propiedad privada) ni tampoco dañaba los sistemas de puentes y galerías (acusación frecuente de los azogueros a los kajchas).

Un índice del umbral de tolerabilidad social respecto a los kajchas serína las respuestas violentas que generaban entre los dueños de ingenios. "Pero era ya tal su fama que deseaban beberle la sangre los dueños: poníanle asechanzas, cercábanlo 30 ó 50 hombres, y unas veces solo y otras con sus compañeros los resistía, acometía y maltrataba con armas enastadas, alfanjes, palos, hondas y piedras, poque su valor y fuerzas todo lo llevaba como a barrisco" (201). Los azogueros (representantes de la burguesía criolla emergente), se alimentan como un vampiro de la vida del trabajador minero, haciendo uso de la violencia para reprimir a Agustín si ofrece resistencia.

Desde esta perspectiva, el kajcha es el minero anómalo que se apropia directamente de los medios para la vida, del producto de su trabajo, habitando así el límite externo de la ley moderna colonial, trayendo sobre sí la condena de una desterritorialización que deja de ser relativa (exceso de valor que habita el margen interior de la ley) para comenzar a ser absoluta (carácter demoníaco del minero que lo instala en el afuera de la ley). Como leemos en la Historia: "Por lo cual llegaron a presumir tenía pacto con el demonio, pues un indio tan pequeño (decían) y de ruin talle y presencia no podía naturalmente ejecutar 
tales resistencias” (201). ${ }^{9}$ De hecho, existe una relación de presuposición recíproca entre la distancia productor-producto por un lado y el carácter ilícito y anómalo de la alianza del minero por otro. El kajcha se convierte no solo en una amenaza, sino en un límite para la moral cristiana y la hegemonía criollo-colonial. La interrupción del sistema acreedordeudor que lleva a cabo el kajcha va acompañada de una alianza con los poderes sobrenaturales que hacen posible tal apropiación al hacer posible la desproporción entre las fuerzas de los azogueros y españoles, y la fuerza del kajcha indígena. La acusación de alianza sobrenatural manifiesta una reacción ante el posicionamiento problemático del kajcha en relación al sistema acreedor-deudor al cual amenaza.

De hecho, tal proximidad con lo demoníaco y con lo sobrenatural es el efecto de una política de apropiación directa de los metales mediante métodos violentos. La estabilidad idéntica de la hegemonía colonial es sometida a una desestabilización violenta por parte del kajcha, quien cruza la frontera de lo tolerable y al hacerlo establece una relación de composición y alianza con lo demoníaco, con la Cosa, con lo abyecto. ${ }^{10} \mathrm{Al}$ cruzar la zona de tolerabilidad, el kajcha está haciendo lo que sabe hacer mejor, es decir: someter el mundo a un devenir, a una metamorfosis y a un cambio permanente. El minero (sobre cuyo trabajo pende el sistema colonial entero) es quien sigue las singularidades de la materia sometiéndolas a una transformación que arrastra consigo las estructuras sociales. Si el minero entra en relaciones de alianza con el demonio, es porque lleva a un paso más su conexión transformadora con la materia, apropiándose de aquello que le está vedado por estar mediado por el sistema acreedor-deudor. Su presunta alianza con el demonio, su caracterización negativa por parte de los guardias y azogueros, es efecto de su situación de exterioridad respecto a la legalidad colonial, cuya génesis se encuentra en el poder transformador de la realidad misma y en la relación productor-producto. La distancia entre el minero y la veta es directamente proporcional a la distancia cultural entre el indígena y el colonizador.

\section{CAPTURA, ESTABILIZACIÓN Y RECODIFICACIÓN DE LA FIGURA DEL KAJCHA}

Arzáns subsume la distancia productor-producto en una reconciliación estabilizadora (transculturación como aparato de captura) como se leerá a continuación: “Con los minadores españoles tenía amistad, y como él es magnánimo y liberal y se hallaba muy descansado por los muchos marcos de plata que sacaba, cualquiera que venía y le representaba su necesidad se la socorría con largueza” (201). Al situar a Agustín en proximidad con los españoles, Arzáns intenta capturar y estabilizar el elemento divergente

\footnotetext{
${ }^{9}$ Arzáns provee de innumerables historias sobre Agustín en las que este "valeroso indio”, como lo llama repetidas veces, está implicado en actos de violencia que Arzáns narra con un lenguaje no del todo desaprobatorio, pero que por motivos de espacio no puedo reproducir en este trabajo. Sin embargo, cabe destacar que Agustín es encarcelado luego de haber resistido a su prisión y que luego es liberado por medio de un decreto de las autoridades de Potosí (201-7).

${ }^{10}$ Ver Taussig el Tío (figura demoníaca de las minas a quien los mineros rinden tributo en coca y cigarros) representa un efecto de la alienación capitalista y de la tensión irreversible entre las fuerzas de producción y las de desarrollo que rige la circulación de mercancías.
} 
y desterritorializado y así disminuir el efecto de distancia existente entre el kajcha y la validez del sistema amenazado por el kajcha. Agustín es generoso, incluso con los españoles, y utiliza su valor (virtud que posee en grado superlativo) contra los aparatos hegemónicos de la colonia y contra los dueños de los medios de producción (sin distinguir entre españoles o criollos): "Sólo con los guardas, con los azogueros como dueños y con otros que le resistían era la muestra de su braveza” (201). Agustín sólo utiliza violencia contra la violencia legal de aquellos que lo separan de su producto, los agentes de la acumulación primitiva y del sistema acreedor-deudor; sin embargo, no parece rebelarse contra el rey de España. En otras palabras, el discurso de Arzáns estabiliza la divergencia de los kajchas recodificándolos en un marco de legalidad. Este marco de legalidad funciona como un régimen de significación en el cual el rey aparece como un significante último que, al entrar en relaciones de redundancia (en significante que funciona como sujeto de otro significante) con el significado, distribuye los signos de un modo sedentario reimpartiendo el significante a partir del significado (por ejemplo: "hay que hacer lo que la ley manda, porque la ley es la ley”). Por un lado, Agustín parece traspasar el umbral de tolerabilidad de la propiedad privada, aunque, por otro lado, tal tolerabilidad no parece infringir el significante último que distribuye los signos en cadena de acreedores y deudores ya que Agustín paga los quintos reales (tributos debidos al rey de España). En el texto de Arzáns, Agustín no cuestiona la legalidad última del sistema, sino que aparece como una transgresión fruto del deseo por la ley.

Arzáns reestratifica a Agustín adjudicándole una buena voluntad que lo atrapa en la cadena de significación colonial propia del sistema acreedor-deudor:

A favor del rey y de la república lo era muy aventajado porque sacando copias de metales los beneficiaba en su trapiche, y forzosamente tenía quintos su majestad, y la república el corriente de la plata, los curas las fiestas, y el culto divino un sobresaliente, porque era en este particular muy devoto y liberal en los gastos. (201)

En otras palabras, Agustín aparece bajo el doble signo de la desestratificación absoluta, demoníaca, liminar y subalterna por un lado, bajo el signo del buen ciudadano, el sujeto valeroso, más español que los españoles, que cuida de los intereses del rey y de la corona por otro. Agustín “aventaja” a los otros tributarios del rey, los excede, va mas allá de ellos ya que al poseer un exceso de metal por vía de la apropiación directa, es mejor tributario que cualquier tributario y más español que cualquier español. Agustín se halla, paradójicamente, más allá de la ley, pero incluido en la ley. Esto indica que Arzáns supone que apropiarse de los medios directos de la vida (sin mediación del intercambio mercantil) deja intactas las bases del sistema acreedor-deudor al mismo tiempo que las alimenta ya que todo excedente de valor se transforma en un excedente de limosna. Agustín posee un exceso de valor, un exceso de metales, que lo hace mejor objeto de captura por parte de la iglesia y del Estado. Si al comienzo Arzáns regulariza, reestratifica y resignifica a Agustín al asignarle una cualidad (el valor que posee en grado superlativo) ahora reintroduce la posibilidad de extraer una diferencia cuantitativa (extracción de plusvalía) al inscribir a Agustín en el sistema acreedor-deudor colonial. De este modo Arzáns reinserta la práctica de los kajchas en una cadena de signos que está regida por el significante 
colonial, que continuamente inyecta deudas en el sistema y vuelve a separar al productor del producto.

La pregunta que surge es: ¿está Arzáns tolerando la apropiación directa de los modos de producción, o está diciendo que un poco de apropiación directa, un poco de mal funcionamiento, un poco de crisis dentro de la distribución de las riqueza no representa una amenaza, porque incluso las contradicciones del sistema pueden ser reguladas, reestratificadas en un sistema a condición de que se reimparta rigurosamente el significado con la erección de otro significante? Arzáns subordina la conexión directa productorproducto a las exigencias de la disyunción negativa que vuelve a reinsertar el objeto de apropiación directa en circulación de tributos separando al productor del producto. El pliegue barroco no llega a ser una herida en el sistema, sino que es la pequeña dosis de caos necesaria para que el capitalismo mercantil y el sistema tributario puedan seguir funcionando. Arzáns está mirando desde la perspectiva del significante colonial como función subordinada de la expansión capitalista, es decir, de la reintroducción de la redundancia del significante, que regulariza cualquier acto de resistencia convirtiéndolo en una transgresión que refuerza la ley y nunca llega a subvertirla. Arzáns acompaña a Agustín en su transgresión, en su recorrido de la distancia entre productor y producto, hasta el origen mismo del significante colonial, hasta su posterior reestratificación y encarcelamiento. Arzáns trae la memoria borrada del trabajador, pero solo con el propósito de volver a borrarla. Por esto, está escribiendo desde la perspectiva del capital, ya que fomenta por un lado la desestratificación de los flujos (circulación del dinero, ruptura de códigos morales binarios), mientras que por otro lado reestratifica estos mismos flujos en el sistema acreedor-deudor del cual ellos mismos escaparon. Sin embargo, Arzáns traza una cartografía de poder, que no puede dejar de marcar la distancia entre el minero y la veta, una distancia que amenaza con desestabilizar el sistema y convertir el pliegue en una herida, en una amenaza de insurrección.

Luego de insistir en que Agustín actúa a favor del rey y de la república, Arzáns muestra cómo el kajcha interrumpe los intereses individuales de los dueños de los medios de producción: "Pero ni justicias ni los interesados miraban buenas partes en Agustín, sino que lo tenían por monstruo infernal y procuraban echarlo del mundo” (201). En otras palabras, ni la ley ni los intereses de los azogueros toleran a Agustín ya que lo consideran un "monstruo infernal”. Aquello que es tolerable por el significante colonial (entendido como significante último del sistema acreedor-deudor) es un monstruo infernal, una Cosa, la cristalización de una multiplicidad anómala e ilocalizable desde el punto de vista de la policía y de los dueños de los medios de producción. La ambivalencia tan propia de Arzáns se explica por la coexistencia de dos perspectivas. Por un lado, al introducir la perspectiva de la redundancia del significante, Arzáns reintroduce la distancia entre el productor y el producto que había sido transgredida por Agustín. Desde esta perspectiva Arzáns introduce una disyunción inclusiva que acepta a Agustín subsumiéndolo en la soberanía del significante colonial, pero bajo el precio de introducir una disyunción exclusiva que insiste en separar al productor del producto. Por otro lado, los azogueros introducen una disyunción exclusiva entre Agustín y cualquier instancia de aceptabilidad, ya que quisieran "echarlo del mundo" por haber producido una conexión directa entre el 
productor y el producto. En otras palabras, Arzáns escribe desde la perspectiva de la Historia con mayúscula (Occidental y Europea), ya que confía en la capacidad del significante y la ley para reestabilizar el sistema, mientras que los dueños de los medios de producción hablan desde la perspectiva del interés privado, que intenta desplazar el límite externo del capital, es decir, "echar del mundo" a quien se apropie del producto.

EL ESPECTRO DEL KAJCHA COMO AMENAZA DE INSURRECCIÓN

La perspectiva de Arzáns es la de aquel que ve en la desviación y divergencia una desterritorialización relativa que debe ser representada en la estabilidad de la ley. La perspectiva de los “interesados” y de la justicia local es la perspectiva del lado interno del sistema que sólo puede caracterizar la desviación y la divergencia como una desterritorialización absoluta que ve en Agustín una figura limítrofe con lo demoníaco. La perspectiva de Arzáns es la perspectiva del que usa la escritura como captura. Por otro lado, la perspectiva de los azogueros es la perspectiva del que utiliza el murmullo anónimo con el propósito de evitar cualquier fuga de flujo de metal. Finalmente, falta la perspectiva del kajcha, del propio Agustín, que se encuentra necesariamente perdida y atrapada en el double-bind de la perspectiva de Arzáns y de la perspectiva de los dueños de ingenios. No obstante, ¿no es acaso posible revertir perspectivas con el propósito de tensar la distancia entre el productor y producto, y explorar las potencialidades de la misma, recorriendo la distancia del mismo modo que el minero recorre la veta, apropiándose del texto de Arzáns, buscando revertir el acto de apropiación del indio por parte del criollo?

La perspectiva hegemónica sólo puede pensar al kajcha a través de la negatividad, del silencio del subalterno, del hiato que introduce el lenguaje y la cultura en la vida desnuda. A pesar de esto, es posible revertir la captura apelando a la espectralidad propia del umbral más desterritorializado del proceso capitalista. Un ejemplo del miedo al kajcha, como espectro de la insurrección, es el del gobernador Escobedo, para quien, según Enrique Tandeter: "kajcha activities also embodied the specter of insurgency" (110). El miedo que producían los kajchas no era tanto el de la desterritorialización relativa de la conexión productor-producto, sino el de las potenciales insurrecciones o desterritorializaciones absolutas que pudiera traer tal apropiación directa de los medios de vida por parte de los indígenas: "The imminent increase in ore quality, which was expected due to the construction of a new access and drainage adit in the Cerro, worried Escobedo because of the incentive it would provide to the kajchas and the popular tumult that he feared would result” (110). Más que el miedo a los efectos de la conexión productiva (que es neutralizado mediante la introducción del significante colonial y del uso negativo de la síntesis disyuntiva), las autoridades coloniales temen a la síntesis disyuntiva abierta que, al recorrer la distancia entre el productor y el producto, haga de la divergencia, la distancia y la desestratificación un objeto de afirmación, produciendo como resultado una desestratificación absoluta que ya no será negativa (como la que fue resultado de la demonización de Agustín) sino afirmativa (buscando la pura forma de exterioridad a la captura colonial). La estigmatización segregativa, el uso restrictivo de la síntesis disyuntiva por parte de la justicia y de los dueños de los medios de producción (el llamar al kajcha 
un "monstruo infernal”) tiene como único propósito abortar la posibilidad de cualquier divergencia, traduciendo la diferencia en términos negativos. Salir de la perspectiva del significante colonial del criollo implicaría ver cómo el miedo a lo que escapa a la distribución arborescente de las cualidades puede erigirse en una línea autónoma de revolución que comience siendo un acontecimiento (desviación mínima) y termine produciendo la muerte del sistema.

Escribiendo un poco antes de la Gran Rebelión de 1781 de Tupac Amaru, Escobedo temía por la desestabilización que pudieran producir los kajchas: "He worried that unrest could extend to the city as migrants arrived from the 'disgruntled' zones and reached the conclusion that 'nothing would be as opportune as constructing some cannons”” (110). Luego que estalla la revolución de Tupac Amaru, la peor amenaza la constituye la conjunción entre las multitudes de indígenas y la subalternidad liminar de los kajchas que habitan el cerro de Potosí. De este modo, la investidura histórica que resulta intolerable, es la de la posible conexión entre la Gran Rebelión de Tupac Amaru y una insurrección de indios mineros que también se apropien directamente de los medios de producción. Un ejemplo del miedo por la posible conexión entre los kajchas y la revuelta indígena lo encontramos en que en 1782, luego de que estalló la revuelta de Tupac Amaru y Tupac Catari, Juan del Pino Manrique decidió enviar tropas a vigilar a los kajchas (110). Lo más temido (la insurrección) sería la afirmación de las distancia entre los productores (ubicados en el umbral de tolerabilidad) y quienes se estaban rebelando contra el régimen de trabajo forzado en las minas (las masas de potenciales trabajadores indígenas). El miedo a la movilización indígena, el miedo a quienes habitan los límites externos del territorio, despierta el terror y las medidas preventivas propias del estado de excepción. El umbral externo del sistema, esto es, la posible conexión entre kajchas y las masas de la Rebelión, es una anticipación, un nayrapacha (pasado-como-futuro), de lo que Silvia Rivera Cusicanqui ve como una de las características más marcadas de los movimientos mineros. ${ }^{11}$

El texto barroco de Arzáns narra las proezas de Agustín, pero estas proezas son reterritorializadas sistemáticamente en un régimen de signos colonial, que cumple tanto con las exigencias de la reconversión continua a la autoridad real como a la reinserción de la figura del kajcha en el régimen acreedor-deudor del cual está escapando. En este sentido, el miedo que produce la desterritorialización absoluta, el encuentro con lo Real, con la vida desnuda que amenaza el territorio de Potosí, es un miedo que va mas allá de la reintroducción del kajcha en el sistema acreedor-deudor. No es el miedo a la suspensión

\footnotetext{
${ }^{11}$ El potencial revolucionario de la práctica subalterna del kajcheo puede ofrecer puntos de resonancia que lo asocian a la Gran Rebelión de 1781 de Amaru-Catari, pero sobre todo a la revolución de 1952. En esta última, los mineros jugaron un rol esencial, con su radical exterioridad, que fue reinscrita en la estabilidad del momento populista posrevolucionario. Como afirma Silvia Rivera Cusicanqui, la tenacidad del pasado indígena (nayrapacha) y la exterioridad de las estrategias mineras resultan inexplicables dentro de la historiografía marxista tradicional (72-3). Entiendo que existe una relación directa entre el contenido del saber minero, el espacio minero distanciado de la mirada estatal, y la inexplicable fuerza revolucionaria de los que son agentes de este saber.
} 
carnavalesca luego de la cual todo sigue igualmente regido por el significante colonial, sino aquel que recorre la distancia entre productor y producto impidiendo la reintroducción del significante colonial y la separación entre productor y producto. En otras palabras, si Arzáns intenta capturar a Agustín y hacerlo pagar sus deudas para con la sociedad es para protegerse de la amenaza de insurrección rechazando el afuera absoluto (la posible conjunción entre masas insurgentes y kajchas) mediante la apropiación inclusiva del enemigo en el territorio amigo. La inclusión subordinante de Agustín es el lado más optimista del barroco criollo, el que no se siente suficientemente interpelado por la espectralidad de la insurgencia, mientras que la exclusión absoluta del kajcha como espectro de la insurgencia, habla mucho más de las potenciales líneas de fuga que quedan abortadas al interior del texto de Arzáns, y que apuntan hacia el límite más externo y más desterritorializado del sistema colonial.

\section{BiBLIOGRAFÍA}

Arzáns de Orsúa y Vela, Bartolomé. Historia de la Villa Imperial de Potosí. Lewis Hanke y Gunnar Mendoza, eds. 3 v. Providence: Brown University Press, 1965.

Bakewell, Peter. Miners of the Red Mountain Indian Labor in Potosí 1545-1650. Albuquerque: University of New Mexico Press, 1984.

Capoche, José Luis. Relación general de la Villa Imperial de Potosí. Lewis Hanke, ed. Madrid: Biblioteca de Autores Españoles, 1959.

Cole, Jeffrey A. The Potosí Mita 1573-1700. Compulsory Indian Labor in the Andes. Stanford: Stanford University Press, 1985.

Deleuze, Gilles. The Logic of Sense. Trans. Mark Lester. New York: Columbia University Press, 1990.

Deleuze, Gilles y Félix Guattari. Anti-Oedipus: Capitalism and Schizoprhrenia. Robert Hurley, Mark Seem \& Helen Lane, trads. Minneapolis: University of Minnesota Press, 1983.

A Thousand Plateaus: Capitalism and Schizophrenia. Brian Massumi, trad. Minneapolis: University of Minnesota Press, 1987.

García Pabón, Leonardo. "Indios, criollos y fiesta barroca en la Historia de Potosí de Bartolomé Arzáns”. Revista Iberoamericana 171-173 (1995): 423-39.

“The Indian as Image and as Symbolic Structure: Bartolomé Arzáns’ Historia de la villa Imperial de Potosí”. Amerindian Images and the Legacy of Columbus. René Jara \& Nicholas Spadaccini, eds. Minneapolis: University of Minnesota Press, 1992. 530-64.

González Casasnovas, Ignacio. Las dudas de la corona: la política de repartimientos para la minería de Potosí(1680-1732). Madrid: Consejo Superior de Investigaciones Científicas, 2000.

Hanke, Lewis y Gunnar Mendoza. Introducción. Historia de la Villa Imperial de Potosí. Bartolomé de Arzáns Orsúa y Vela. 3 v. Providence: Brown University Press, 1965. 1: xxvii-clxxxi.

Herrmann, Gina. “Amazonic Ambivalence in Imperial Potosí”. MLN 114, 2 (1999): 31540. 
Marx, Karl. Capital. A Critique of Political Economy. v. I. Ben Fowkes, trad. New York: Vintage Books, 1977.

Nietzsche, Friedrich. On the Genealogy of Morals. The Basic Writings of Nietzsche. Walter Kaufmann, trad. \& ed. New York: The Modern Library, 2000. 437-599.

Rivera Cusicanqui, Silvia. "La raíz: colonizadores y colonizados”. Violencias encubiertas en Bolivia. Coord. Xavier Albó y Raúl Barrios, coords. La Paz: CIPCA-Aruwiyi, 1993. 27-139.

Saignes, Thierry. Caciques, Tributes and Migration in Southern Andes. Indian Society and the 17th Century Colonial Order (Audiencia of Charcas). London: University of London, 1985.

Spivak, Gayatri Chakravorty. “Subaltern Studies: Deconstructing Historiography”. Selected Subaltern Studies. Ranajit Guha and Gayatri Chakravorty Spivak, eds. New York: Oxford University Press, 1988. 3-32.

Tandeter, Enrique. Coercion and Market. Silver Mining in Colonial Potosí, 1692-1826. Albuquerque: University of New Mexico Press, 1993.

Taussig, Michael T. The Devil and Commodity Fetishism in South America. Chapel Hill: University of North Carolina Press, 1980.

Williams, Gareth. The Other Side of the Popular. Neoliberalism and Subalternity in Latin América. Durham: Duke University Press, 2002.

Zavala, Silvio. El servicio personal de los indios en el Perú. I: Extractos del siglo XVI. México: El Colegio de México, 1978. 